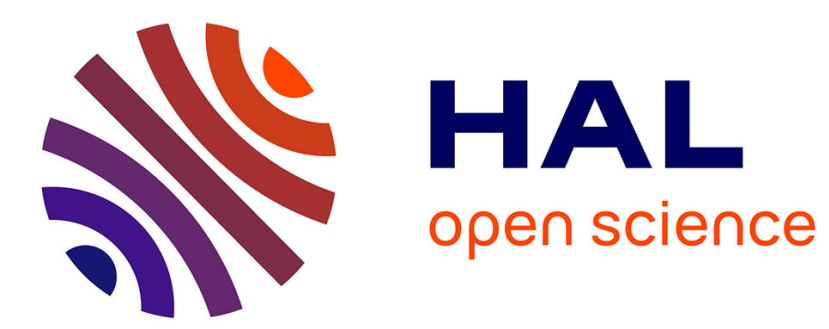

\title{
Robotic reoperation for gastro-gastric fistula after laparoscopic Roux-en-Y gastric bypass (with video)
}

F. Reche, B. Froissart, A. Mancini

\section{To cite this version:}

F. Reche, B. Froissart, A. Mancini. Robotic reoperation for gastro-gastric fistula after laparoscopic Roux-en-Y gastric bypass (with video). Journal of Visceral Surgery, 2019, 156, pp.263 - 265. 10.1016/j.jviscsurg.2019.01.008 . hal-03486510

\section{HAL Id: hal-03486510 https://hal.science/hal-03486510}

Submitted on 20 Dec 2021

HAL is a multi-disciplinary open access archive for the deposit and dissemination of scientific research documents, whether they are published or not. The documents may come from teaching and research institutions in France or abroad, or from public or private research centers.
L'archive ouverte pluridisciplinaire HAL, est destinée au dépôt et à la diffusion de documents scientifiques de niveau recherche, publiés ou non, émanant des établissements d'enseignement et de recherche français ou étrangers, des laboratoires publics ou privés.

\section{다)(1) $(5$}

Distributed under a Creative Commons Attribution - NonCommercial| 4.0 International 


\title{
Title: Totally robotic revision for gastro-gastric fistula after laparoscopic Roux-en-Y gastric bypass (with video)
}

\author{
Authors: Fabian Reche ${ }^{1,2}$, Bruno Froissart $^{3}$, Adrian Mancini $^{1}$
}

1 Department of Digestive Surgery, Grenoble Alps University Hospital, CS 10 2017, 38043

Grenoble cedex, France

2 CNRS, UMR 5525, TIMC-IMAG, Domaine de la Merci, 387043 Grenoble, France

3 Hepato-Gastro-Enterology outpatient private clinic "Les Cèdres", 38000Grenoble, France

Correspondence to: Fabian RECHE, MD, Department of Digestive Surgery, Grenoble Alps University Hospital, CS 10 217, 38043 Grenoble cedex, France

Tel: 33.4.76.76.53.71. Fax: 33.4.76.76.87.80. E-mail: freche@chu-grenoble.fr 


\section{$\underline{\text { Keywords }}$}

Robotic surgery; Gastric bypass; obesity surgery; gastrogastric fistula; revisional surgery

\section{Compliance with Ethical Standards}

Ethical Approval: All procedures performed in studies involving human participants were in accordance with the ethical standards of the institutional and/or national research committee and with the 1964 Helsinki declaration and its later amendments or comparable ethical standards.

Informed Consent: Informed consent was obtained from all individual participants included in the video.

Conflict of Interest: The authors declare that they have no conflict of Interest

Gastrogastric fistula (GGF) is a well-known complication after Roux-en-Y Gastric Bypass (RYGBP) with an incidence ranging from $0 \%$ to $6 \%(1)$. Weight regain and epigastric pain, are the most common symptoms. An upper gastrointestinal (UGI) contrast study (+/- CT scan with ingestion) combined with an endoscopy are used to make the diagnosis. Some GGF may be treated endoscopically but with poor results (2), especially for those type II GGF, located in the distal part of the gastric pouch less $<2 \mathrm{~cm}$ above the gastrojejunostomy (3). In these reoperative cases, robotic assistance may provide great benefit for both surgeon and patient in comparison with conventional laparoscopy.

This video shows the case of a 48-year-old woman with past medical history of laparoscopic RYGBP (LRYGBP) for class III obesity (initial BMI $53 \mathrm{~kg} / \mathrm{m}^{2}$ ), associated with obstructive sleep apnea syndrome and type 2 diabetes. Because this patient complained about weight regain and epigastric pains, an upper gastrointestinal endoscopy was performed. This endoscopy showed an abnormal communication between alimentary limb, at the level of gastrojejunal anastomosis and the excluded stomach. An UGI contrast study was performed and 
confirmed a Type II GGF. It was decided in this case to perform a totally robotic revision of the LRYGBP using the robotic platform. This video shows the different steps necessary to perform this reoperation. Six ports were necessary and placement was shown in figure 1. The robot was docked and positioned at the patient's left shoulder. The different steps were careful adhesiolysis, en-bloc resection of the gastrojejunostomy which allowed to expose the fistula. A stapling of gastric pouch and excluded stomach was then performed. Closure of the fistula on the excluded stomach was completed using a continuous barbed suture with epiploplasty. Lastly, a new gastrojejunal anastomosis was performed hand-sewn in one fullthickness layer, in a running fashion using an absorbable barbed suture and fibrin sealant application. The operative time was 105 minutes. Postoperative course was uneventful. An UGI contrast study was performed at day 1 and the patient was discharged at day 3. Robotic platform, in those redo procedures, could provide greater comfort and precision to the surgeon, and may offer to patients the benefits of a mini-invasive surgery with greater security. However, this remains to be validated in future studies comparing robotic approach and laparoscopic approach in bariatric surgery. This video is usefull for all surgeons having to manage a patient with a gastro-gastrique fistula after Roux-en-Y gastric bypass.

Figure 1. Ports disposition for robotic access

Figure 2. Demonstration of the type II GGF after en-bloc resection of the gastrojejunostomy

Figure 3. Closure of the fistula on the excluded stomach side

Figure 4. Final aspect after revisional surgery and creation of a new gastrojejunostomy 


\section{$\underline{\text { References }}$}

1 Carrodeguas L, Szomstein S, Soto F, et al. Management of gastrogastric fistulas after divided Rouxen-Y gastric bypass surgery for morbid obesity: analysis of 1292 consecutive patients and review of literature. Surg Obes Relat Dis 2005;1:467-74

2 Fernandez-Esparrach G, Lautz DB, Thompson CC. Endoscopic repair of gastrogastric fistula after Roux-en-Y gastric bypass: a less invasive approach. Surg Obes Relat Dis 2010;6:282-8.

3 Ribeiro-Parenti L, De Courville G, Daikha A, Arapis K, Chosidow D, Marmuse J-P. Classification, surgical management and outcomes of patients with gastrogastric fistula after Roux-En-Y gastric bypass. Surg Obes Relat Dis 2016;13:243-8. 


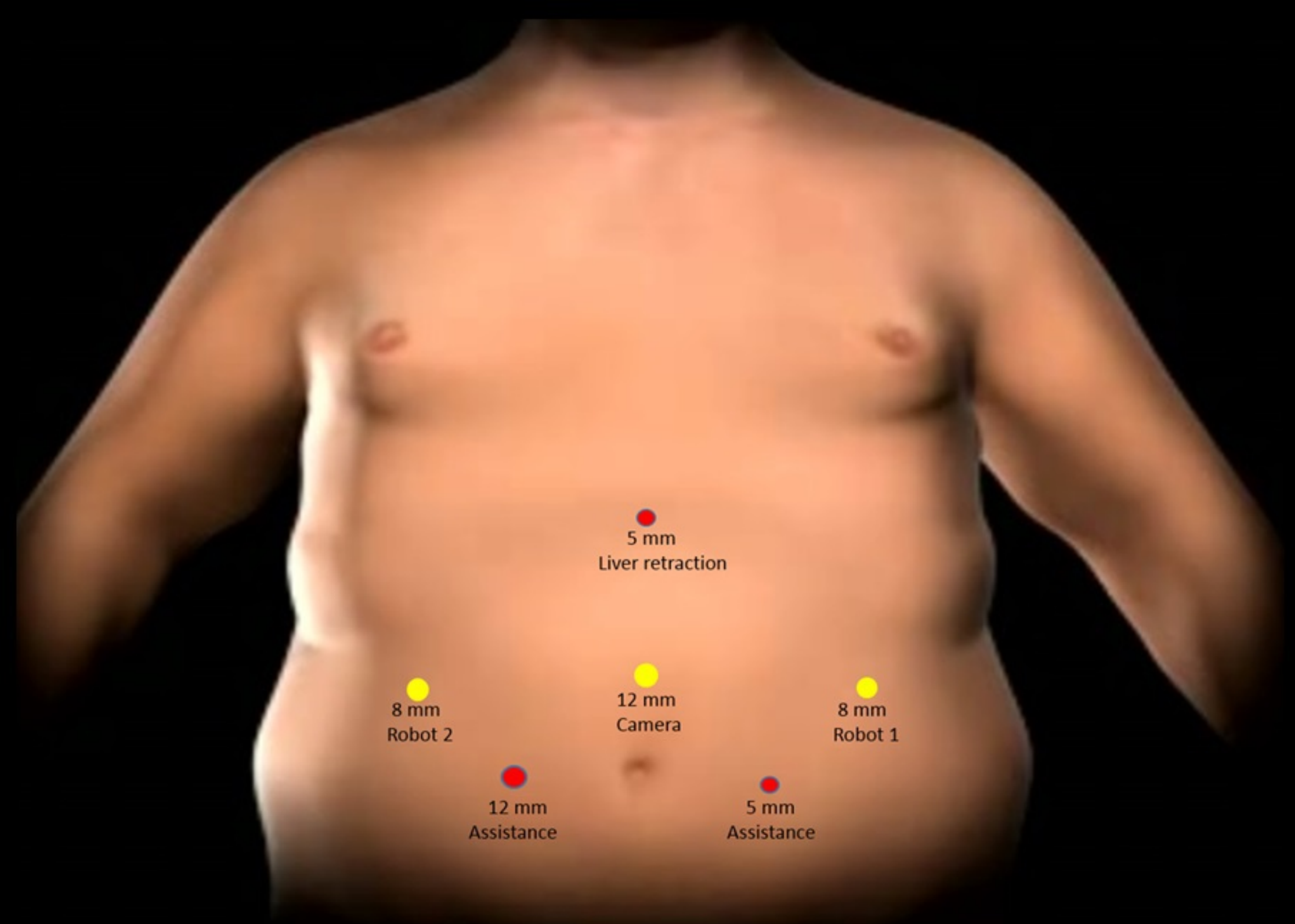




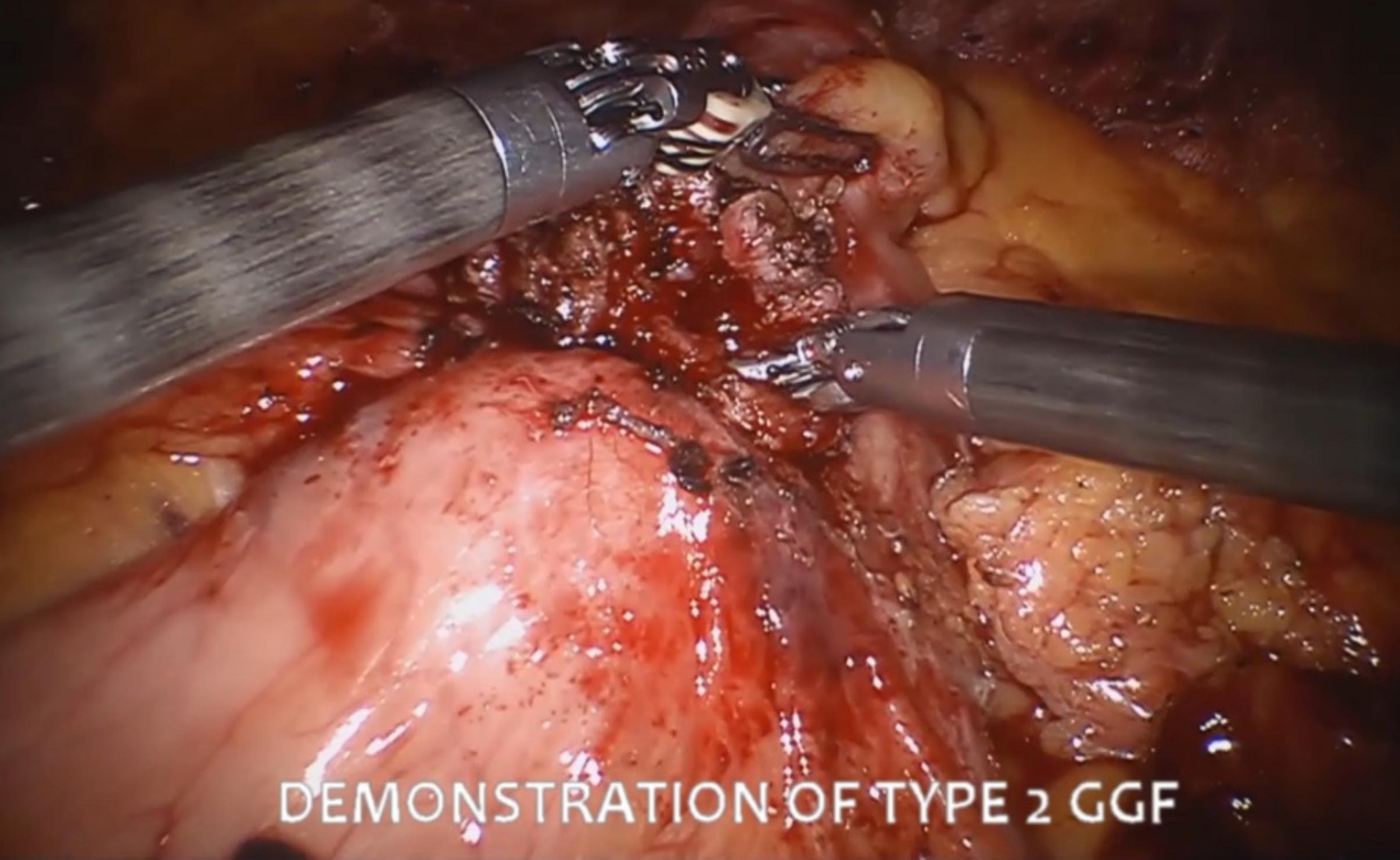




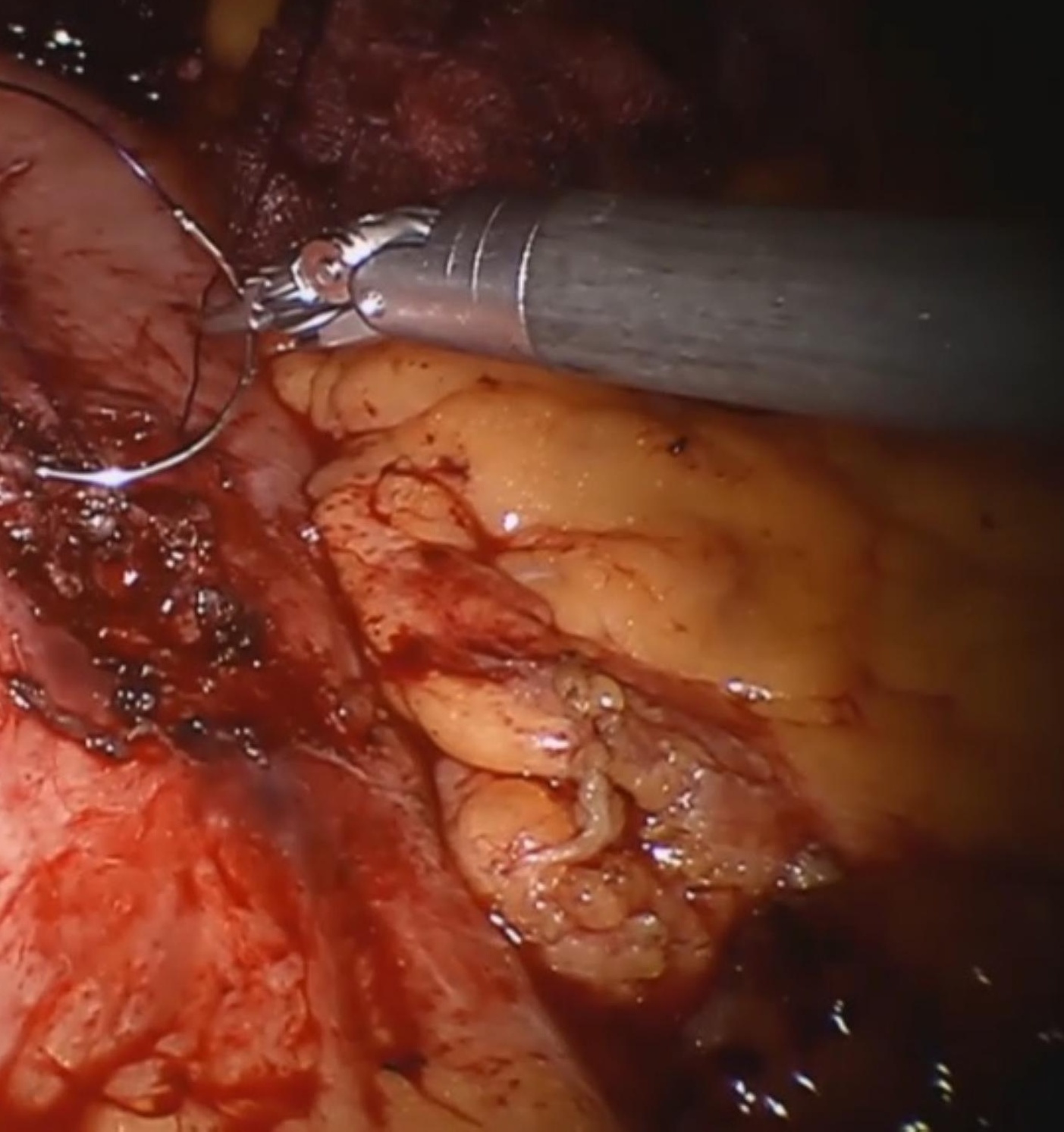




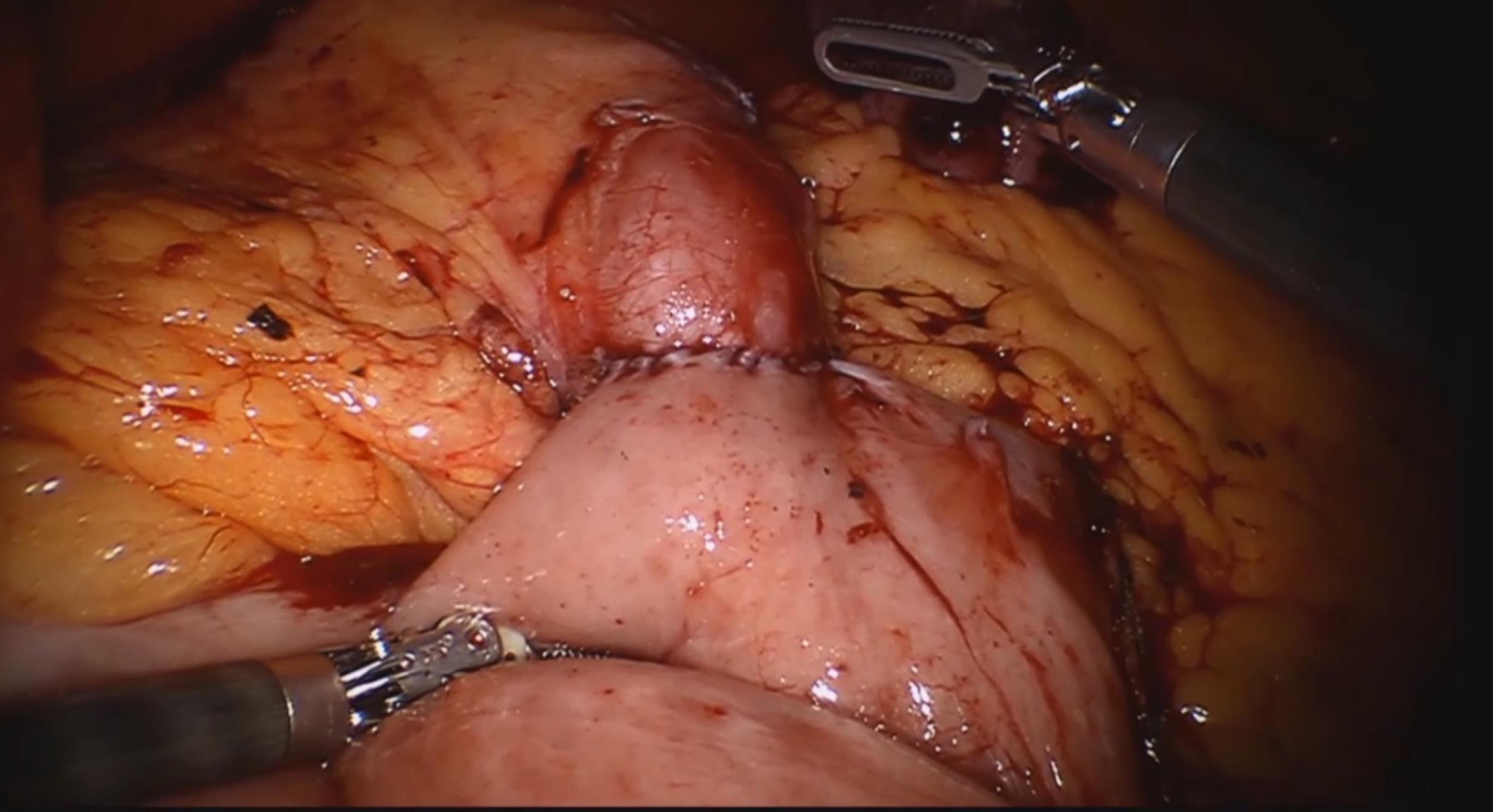

